\title{
Reply to Ozkan et al. regarding 'Acoustic radiation force impulse elastography for detection of renal damage in children'
}

\author{
Cemil Göya $\cdot$ Aydın Ece $\cdot$ Cihad Hamidi
}

Received: 25 August 2014 / Accepted: 17 September 2014 /Published online: 10 October 2014

(C) Springer-Verlag Berlin Heidelberg 2014

Sir,

Many thanks to Ozkan et al. [1] for their comments on our article "Acoustic radiation force impulse elastography for detection of renal damage in children" [2]. Their criticisms regarding the limitations caused by the image acquisition technique have been reported previously [3-5].

We attempted to design the study protocol so as to reduce these known limitations of elastography. We obtained 15 measurements in total, 5 measurements from each of the 3 segments, from each kidney. Furthermore, we performed evaluations both subjectively and quantitatively.

Although we did not compare measured values among different segments, these comparisons can be done in the normal kidneys of the control group. Because kidney damage may be global or segmental, we performed elastographic measurements both globally subjectively, and quantitatively by segment.

To decrease inaccuracy related to anisotropy and to compression exerted via the transducer, we performed a large number of measurements. We also calculated inter- and intra-observer variability. Elastography is similar to ultrasound in that it is both patient- and operator-dependent, an issue we discussed in our paper. We made efforts to decrease these constraints.
We agree that further studies are needed, in particular to determine optimum cut-off values for diagnostic categories.

Conflicts of interest None

\section{References}

1. Ozkan F, Menzilcioglu MS, Duymus M et al (2014) Acoustic radiation force impulse elastography for evaluating renal parenchymal stiffness in children. Pediatr Radiol. doi:10.1007/s00247-014-3174-y

2. Goya C, Hamidi C, Ece A et al (2014) Acoustic radiation force impulse (ARFI) elastography for detection of renal damage in children. Pediatr Radiol. doi:10.1007/s00247-014-3072-3

3. Grenier N, Gennisson JL, Cornelis F et al (2013) Renal ultrasound elastography. Diagn Interv Imaging 94:545-550

4. Bruno C, Caliari G, Zaffanello M et al (2013) Acoustic radiation force impulse (ARFI) in the evaluation of the renal parenchymal stiffness in paediatric patients with vesicoureteral reflux: preliminary results. Eur Radiol 23:3477-3484

5. Syversveen T, Midtvedt K, Berstad AE et al (2012) Tissue elasticity estimated by acoustic radiation force impulse quantification depends on the applied transducer force: an experimental study in kidney transplant patients. Eur Radiol 22:2130-2137

C. Göya $\cdot$ C. Hamidi $(\bowtie)$

Department of Radiology, Medical School, Dicle University,

Yenişehir, 21280 Diyarbakir, Turkey

e-mail: cihad5@hotmail.com

A. Ece

Department of Pediatrics, Medical School, Dicle University,

Diyarbakir, Turkey 